\title{
Emergency Preparedness and Perceived Competence of Health Care Providers in Disaster: An Egyptian Study
}

\author{
Azza Hassan Mohamed Hussein, Assistant Professor \\ Nursing Administration, Faculty of Nursing, Alexandria University \\ Naglaa Abd El Aziz Mahmoud, Lecturer \\ Nursing Administration, Faculty of Nursing, Alexandria University
}

\begin{abstract}
An effective healthcare system response to various disasters is paramount; however pertinent related research is still in its infancy, especially in middle- and low-income countries. Objective: Assess nurses' and physicians' familiarity with readiness in managing disaster and emergency situations. Setting: The emergency department at Alexandria Main University hospital. Subjects: 108 nurses and 42 physicians. Tool: The 47-item Disaster Readiness Questionnaire that incorporated the Emergency Preparedness Information Questionnaire (EPIQ-45 items) and two open ended-questions. Results: The findings revealed that nurses are less likely to report familiarity than physicians in managing emergency and disaster situations. Familiarity with emergency preparedness terms and activities, incidents command system and ethical issues in triage, and epidemiology and surveillance are rated as the highest domains by the participants. Conclusion: Both nurses and physicians had significant gaps in their familiarity with the emergency preparedness in disaster management and raised concerns about lack of training, unavailability of strategic and operational plans, and unfamiliarity with roles, procedures and assignment in disaster situations. Recommendations: It is proposed that hospital managers must look for opportunities to effectively adopt national standards to manage disasters and include nurses and physicians in major related learning activities, because experience has suggest a somewhat low overall perceived competence in managing disaster situations.
\end{abstract}

Keywords: Disaster, Emergency, Preparedness Health care providers.

\section{Introduction}

Disaster preparedness and disaster management are terms that are rarely mentioned in the organized academic training of nursing and medical study. The disasters of the past decade have led health care systems worldwide to accord increasing priority to emergency management. The past few years in particular, have produced a demand in the hospitals' workforce for a higher level of emergency preparedness and competency ${ }^{(1)}$ and forced them to confront the vulnerabilities of their emergency preparedness systems and to begin embracing better practices to improve their ability to manage disasters ${ }^{(2)}$.

During disaster situations, Powers (2009) suggested that between 66 and 93 percent of the patients attended to healthcare facilities, typically within 30 minutes of a disaster having happened and without facility staff having received prior warning $^{(3)}$. It might be accepted, in this way, the medical professionals, especially the emergency department employees (nurses and physicians) must be included in all phases of disaster planning, as well as in the immediate response to this event ${ }^{(4)}$. Nevertheless, they are not often among the 
first responders in the event of these disasters and are the frontlines of preparedness.

Adequate preparation has become particularly important following the problematic response seen during recent crises. This is due to the fact that the general population expects public service agencies to rapidly mobilize to help the injured and the community in general should a disaster strikes. Mitigation of the overall effect of any specific inadequacy may be improved by increased knowledge, involvement in planning and engaging employees with different types of exercises. Many public and local institutions have begun to develop some form of preparedness and response plans with the growing threat of naturally occurring or man-made global threats ${ }^{(5)}$.

Emergency preparedness as defined by Slepski (2005) is comprehensive skills, abilities, knowledge, and actions that are needed to respond and prepare for a threat, actual or suspected ${ }^{(6)}$. During major disaster events, the demand for physicians ${ }^{(7)}$ and nurses is much greater than the demands for any other healthcare professionals ${ }^{(8)}$. The nurse must be familiar with needed core abilities and must possess the knowledge ${ }^{(9)}$ to be an effective team member ${ }^{(10)}$. Nurses and physicians should anticipate an expanded role during disaster events to include caring for the sick and injured ${ }^{(9,11)}$, infection control, contingency planning to prevent further damage, triage, mass immunizations, mass evacuations, and treatment for mass casualties ${ }^{(12)}$.

In order to prepare the healthcare system and healthcare personnel to meet the health needs of populations influenced by disasters, educational programs have been developed by multiple academic agencies, hospitals, professional organizations, governments, and non-governmental organizations. Lacking standards for best practices as a foundation, many organizations and institutions have established core competencies that they considered the essential knowledge and skills in disaster management for healthcare personnel $^{(13)}$. Competencies are defined as the knowledge, skills, and abilities necessary for the effective and efficient functioning of an organization or $\operatorname{profession}^{(14)}$.

For instance, Bahrami et al. (2015) identified five main themes for nurses including: management competences, ethical and legal competences, team working, personal competences, and specific technical competencies ${ }^{(15)}$. Other competencies were described for teaching emergency preparedness to students in the health care professions. These competencies encompassing: emergency management and preparedness, terrorism and public health emergency preparedness, public health surveillance and response systems, as well as patient care for disasters ${ }^{(16)}$. In the study of Slepski (2007), the emergency preparedness and professional competency of registered nurses and physicians during disaster response were examined. Basic clinical care and triage were the most frequent response skills reported; the areas wherein respondents felt least prepared were disaster-specific response skills and systems issues ${ }^{(17)}$. Furthermore, health care providers' competence in disaster management was measured by Wisniewski et al. (2004) to identify workforces' perceived familiarity with 11 dimensions. These domains include: emergency preparedness terms and activities, incident command system, ethical issues in triage, epidemiology and surveillance, isolation/quarantine, decontamination, communication/ connectivity, psychological issues, care of special populations, accessing critical resources, and overall familiarity with emergency and disaster preparedness $^{(18)}$.

Most of the existing research has occurred in high-income countries, such as the US and has focused on the health system's disaster management or the capability to supply medical services during disasters ${ }^{(19,20)}$. However, there is scarce 
available information from low- and middle-income countries. As a scientific discipline and specialization, the concept of disaster management is highly undeveloped in Egypt ${ }^{(21)}$.

Egypt is a country that has been seriously influenced by numerous types of disasters including natural and man-made disasters. Natural disasters known in Egypt are: flash floods, earthquake. In addition, major fires, transportation accidents, desertification, climate change, pollution, pandemic diseases, as well as leakage of hazardous substances are the most frequent man-made disasters that happened in Egypt $^{(22)}$.

However, in Egypt, Abd Elazeem et al. (2011) studied professional and paramedical staff's awareness about the internal disaster management plan in the hospital. The results showed low level of awareness about all items of the disaster plan $^{(23)}$. Furthermore, Diab and Mabrouk (2015) examined the effect of learning materials on the knowledge and attitude of the nurses in disaster preparedness. Only $12.6 \%$ of the nurses had satisfactory awareness about hospital disaster preparedness, and $37.5 \%$ had positive attitude towards disaster management ${ }^{(24)}$

\section{Aims of the Study}

The aims of the study were threefold; first, to assess and compare nurses' and physicians' familiarity with readiness in managing disaster and emergency situations, second to identify the barriers and recommendations to improve their readiness in disaster and emergency, and third to determine the relationship between participants' familiarity with readiness in managing disaster and emergency events and their demographic and professional data.

\section{Materials and Method}

\section{Materials}

Design: A descriptive comparative approach was selected for this study.

Setting: The study was done in the emergency department at Alexandria Main University hospital. The department is ready to receive victims of disasters as well as all emergency cases. For instance, victims of large-scale disasters and cases of gun-shot, burn, accident and life threatening illnesses are included. This hospital is a multicampus medical building and among the largest university hospitals in Alexandria and serves a large number of patients and disaster victims.

Subjects: The study participants comprised all nurses and physicians who were available and willing to participate in the study during the time of data collection in the studied emergency department $(\mathrm{N}=161)$. Of these, 150 completed and returned the questionnaire, representing a valid response rate of $93.2 \%$. The response rate was 108 out of $114(94.7 \%)$ for nurses and 42 out of $47(89.4 \%)$ for physicians.

\section{Tool:}

Tool I: Disaster Readiness Questionnaire

Disaster Readiness Questionnaire involved a tool that contains 47 questions divided into two main sections. The tool incorporates all the components of the Emergency Preparedness Information Questionnaire (EPIQ) developed by Wisniewski et al. (2004) ${ }^{(18)}$ and adopted by the current researchers. It was used to assess participants' responses on the EPIQ to identify their familiarity with readiness in managing disaster and emergency situations though 45 items grouped under 11 dimensions: familiarity with emergency preparedness terms and activities ( 7 items), knowledge of the Incident Command System ICS and healthcare providers role within it (8 items), ethical issues in triage (4 
items), epidemiology and surveillance (4 items), isolation/quarantine (2 items), decontamination (3 items), communication/ connectivity ( 7 items), psychological issues (4 items), care of special populations (2 items), accessing critical resources (3 items), and overall familiarity with emergency and disaster preparedness (1 item). The responses were measured using a 5 -point rating scale ranging from strongly familiar (5) to strongly unfamiliar (1). The higher the score is, the higher the familiarity with readiness in managing disaster.

The second section of the tool was developed by the current researchers; it consists of two open ended questions. The first question asked about barriers facing the healthcare providers' readiness in managing disaster and emergency events. The second one asked about the recommendations for improvement of participants' readiness in managing disaster and emergency events. In addition, demographic and professional data consist of work unit, age, sex, educational level, and both total year of experience and in work unit, attendance of previous training program about disaster and emergency preparedness and the subsequent areas included in this training.

\section{Method}

- Before embarking in data collection, an informed consent was obtained from each participant to be involved in the study. Participation was voluntary. Privacy and confidentiality of data were maintained.

- The questionnaire was translated into Arabic by the researchers. A pilot study was carried out on 10 nurses and 5 physicians who were working in the hospital units, other than the studied department, to check the clarity of the statements.

- The questionnaire was tested for its content validity by five experts in the same field of the study and the needed modifications were carried out as adding other different biological agents such as (i.e. anthrax, smallpox, T.B, SARS, etc.), use the word "specify" instead of the word "match" in "Match antidote and prophylactic medications to specific biological/chemical agents", state example for each category of the exposure to biological agents "History and physical assessment surveillance data for creating high index of suspicion that a patient has been exposed to a Category A (i.e. anthrax, plague, smallpox etc.), B (i.e. Q fever, Hepatitis A etc.), or C (i.e. Yellow fever, influenza virus etc.). Also, the responses on the scale were modified from very familiar (1) to unfamiliar (5) in the original form; to strongly familiar (5) to strongly unfamiliar (1).

- The reliability of the internal consistency was done using Cronbach's alpha for the EPIQ and the result proved its reliability ( $\alpha$ 0.789), while the statistical significance level was set at $p<0.05$.

- The questionnaire was completed in about 45 minutes by each participant in the morning and afternoon shifts. Data collection took about three months starting from mid of March till the end of June, 2014.

\section{Ethical considerations:}

- The Ethics Committee of the Faculty of Nursing, Alexandria University has reviewed and approved the protocol of this study.

- After giving necessary information before the distribution of the questionnaire, informed consent was obtained from all participants.

- Confidentiality of data and participants' privacy and anonymity were assured. 


\section{Statistical Analysis}

After data were collected, they were revised, coded and fed to statistical software SPSS IBM version 20. All statistical analyses were done using two tailed tests and alpha error of 0.05. All discrete items concerning perception of knowledge were summed together and mean score was calculated for each domain. The following statistical tests were used: descriptive statistics in the form of frequencies and percent were used to describe the categorical data variables and mean with standard deviation for scale data. To test the differences between nurses' and physicians' familiarity with readiness in managing emergency preparedness and perceived competence scores, independent samples ttest was used, while Pearson $X 2$ test was used to test differences in responses of barriers and recommendations. Linear regression was used to predict a dependent variable (nurses' and physicians' overall familiarity) on the basis of continuous and/or categorical independents (demographic and professional characteristics) and to determine the effect size of the independent variables on the dependent, to rank the relative importance of independents and to understand the impact of covariate control variables. The impact of predictor variables is usually explained in terms of regression coefficient (B) which means the amount in change in the outcome per unit change in the predictor. The stepwise linear regression methods were used to determine automatically which variables to add or drop from the model and identifying the most significant predictors.

\section{Results}

\section{Participants' demographic and professional characteristics}

It was found that $42.6 \%$ of nurses comparing to $73.8 \%$ of physicians were in the age group of $<30$ year. The majority of nurses $(90.7 \%)$ were female and $83.3 \%$ of physicians were males. About $42.0 \%$ of nurses comparing to $92.9 \%$ of physicians had less than 10 total years of experience. Also, $29.6 \%$ of nurses had between five to less than 10 years of experience in their work units comparing to $76.2 \%$ of physicians who had less than five years. The majority of nurses $(88.0 \%)$ had Diploma Degree in Nursing and $71.4 \%$ of physicians had Baccalaureate Degree in Medicine. Furthermore, $89.8 \%$ of nurses comparing to $83.3 \%$ of physicians did not attend any training related to disaster and emergency preparedness. Only $8.3 \%$ of nurses and $11.9 \%$ of physicians attended training programs in first-aids and advanced life support.

\section{Familiarity with readiness for managing emergency and disaster events}

Table (1) indicates that the mean score of the participants on the overall EPIQ scale was 2.72 \pm 0.74 ; denoting that the participants were to some extent unfamiliar with the information and competencies required in emergency preparedness. Also there was no significant difference between the overall mean familiarity scores of nurses $(2.69 \pm 0.80)$ and of physicians $(2.78 \pm 0.56)$, $(\mathrm{P}=0.483)$. The highest mean scores were found on familiarity ethical issues in triage and epidemiology and surveillance as rated by the participants $(2.99 \pm 0.90)$ and $(2.98 \pm 0.95)$, respectively. The results of the paired t-tests were found to be statistically significant; indicating that physicians were more familiar with ethical issues in triage, epidemiology and surveillance, and emergency preparedness terms and activities $(3.58 \pm 0.77,3.55 \pm 0.66,3.15 \pm 0.60)$ than nurses $(2.76 \pm 0.84, \quad 2.76 \pm 94$, $2.75 \pm 0.91), \quad(\mathrm{P}=<0.0 .001, \quad \mathrm{P}=<0.0 .001$, $\mathrm{P}=0.003)$, respectively. On the contrary, the least participants' scores were found on accessing to critical resources $(2.44 \pm 0.99)$, which was significantly lower in physicians $(2.10 \pm 0.74)$ than in nurses $(2.59 \pm 1.04)$, $(\mathrm{P}=0.001)$. 


\section{Barriers and recommendations for improving readiness in disaster and emergency situations}

Table (2) shows that there was no significant difference between nurses' and physicians' responses of barriers and recommendations for improving readiness in managing disasters and emergency situations. Also, $87.0 \%$ of nurses and $85.7 \%$ of physicians mentioned that the hospital had no national health standards, protocols, strategic or operational plans for disaster and emergency preparedness and management. Furthermore, the majority of nurses $(90.7 \%)$ and physicians $(92.8 \%)$ reported unfamiliarity with their roles, procedures and assignments followed in disasters management. More than two thirds of nurses $(67.6 \%)$ and physicians $(76.2 \%)$ found that they never took part in setting up and running of disaster and emergency preparedness.

In relation to recommended improvements, $86.1 \%$ of nurses and $88.1 \%$ of physicians asked for national standards, strategic and operational work plans, policies, and guidelines related to disaster management. Also, 92.6\% of nurses and $83.3 \%$ of physicians found that they are in need for planned trainings in areas such as first aid, triage and CPR, etc. In addition, $81.5 \%$ of nurses and $73.8 \%$ of physicians need better work organization in disaster and emergency events. However, $73.1 \%$ of nurses and $78.6 \%$ of physicians reported the need to have well designed educational content related to emergency preparedness in disaster management in their undergraduate curricula. In the same line, $77.8 \%$ of nurses comparing to $88.1 \%$ of physicians addressed the need for adequate number of qualified healthcare providers.

Mixed linear regression models of nurses' and physicians' demographic and professional characteristics and their overall familiarity with readiness in managing disasters
In relation to nurses, table (3) reflects that the regression analysis model shows that the R2 $=0.096$ which means that only $9.6 \%$ of nurses' overall familiarity is explained by their demographic and professional characteristics with $\mathrm{F}$-value $=$ $2.176(\mathrm{P}=0.063)$, this indicates that the model is insignificant (Model 1). Also, there is no significant variance in the degree of the associations of overall nurses' demographic and professional characteristics (independent variables) with the dependent variable. In predicting nurses' overall familiarity, it is found that their overall familiarity was significantly associated only with female nurses $(\beta=0.261, \mathrm{t}=2.565, \mathrm{P}=0.012)$ that means female nurses are more familiar than males on the overall familiarity with readiness for disasters, followed by inverse, insignificant associations with each of nurses" educational level $(\beta=-0.143, \mathrm{t}=-1.493)$, unit experience $(\beta=-0.111, \mathrm{t}=-0.494)$, attending training $(\beta=-0.044, \mathrm{t}=-0.464)$ and age $(\beta=-$ $0.037, \mathrm{t}=-0.161)$.

The regression analysis model shows that $\mathrm{R} 2=0.121$ this implies that only $12.1 \%$ of physicians' overall familiarity with emergency preparedness and perceived competence in disaster is explained by their demographic and professional characteristics with $\quad$ F-value $=0.992$, $(\mathrm{P}=0.436$, Model 2). The model is insignificant as no significant variance was found in the degree of associations of overall physicians' demographic and professional characteristics (independent variable) with the dependent variable. Furthermore, in predicting physicians' overall familiarity, it was found that age is the strongest, insignificant variable associated with physicians' familiarity $(\beta=0.330, t=1.379, P=0.176)$ followed by inverse insignificant associations with each of unit experience $(\beta=-0.313, \mathrm{t}=-1.348$, $\mathrm{P}=0.186)$, female physicians $(\beta=-0.182, \mathrm{t}=-$ $1.153, \mathrm{P}=0.257)$, educational level $(\beta=.098$, $\mathrm{t}=.481, \mathrm{P}=.634)$ and attendance of training $(\beta=0.073, \mathrm{t}=0.454, \mathrm{P}=0.653)$. 


\section{Discussion}

It is not surprising to find the participants in the present study had considerable gaps in their familiarity with the knowledge and competence needed to function effectively in disaster and emergency situations $(2.72 \pm 0.74)$. This finding is similar to Wisniewski et al. (2004) who found that knowledge of nurses in disaster preparedness was lower than expected ${ }^{(18)}$. Similar finding was reported by Seyedin et al. (2015) who used an adapted form of the EPIQ and found that the average perceived knowledge of was $2.43 \pm 1.01^{(25)}$.

This result is understandable when more than two thirds of the participants in the present study claimed that they had never taken part in any training with regards to the setting-up and running of disasters and emergency preparedness. Also, it was not well documented how and to what extent nursing and medical schools were teaching this content in their curricula and to what extent participants learned about disaster plans in their workplace. In addition, unavailability of national standards and protocols of practice and lack of integration within the hospital and with other healthcare organizations, lack of work organization and shortage in emergency department workforce could be other contributing factors. These findings might explain the insignificant associations of most of the demographic and professional characteristics of the participants and their overall familiarity in managing disasters. However, accurate data derived from selfreports such as EPIQ can be compromised by the problem of subjectivity. To ensure accurate parameter estimates and valid research results, the problem of subjective data needs to use in addition other objective measures and assesses the views of different groups of participants such as managers and victims to compare the data to have more valid data.

Hsia et al. (2011) reported similar findings that as few as $14 \%$ of hospitals (and as high as 76\%) among the surveyed hospitals in sub-Saharan Africa, these hospitals had no training and supervision in place $^{(26)}$. Therefore, Kitt et al. (2005) found that much planning, drilling, evaluating, revising and preplanning are required to successfully handle sudden events that injure humans, destroy property, and overwhelm responders. Hospitals must not only have an external disaster plan, but a plan for internal disasters as well ${ }^{(27)}$. Likewise, Baack and Alfred (2013) found that most nurses are not confident in their abilities to respond to major disaster events. The nurses who were confident were more likely to have had actual prior experience in disasters situations ${ }^{(28)}$.

Likewise, Seyedin et al. (2015), found that there is no relationship was found between nurses' demographic data (age, gender and their experience in ED) and their level of knowledge ${ }^{(25)}$. The findings of the present study could be explained in the context of other personal and organizational factors, rather than the demographic characteristics, which were not investigated in this study. Therefore, it is important in the future to develop research to identify the factors that can contribute directly or indirectly to health care familiarity with knowledge and competence in emergency preparedness in disaster.

Whilst some of the results of the present study were expected, others were more surprising. It was found that participants' familiarity with the emergency preparedness terms and activities, ethical issues in triage, epidemiology and surveillance were recorded as the top ranked areas, which were known more to physicians than nurses. These findings were inconsistent to some extent with Seyedin et al. (2015) who reported that familiarity with triage was the highest domain rated by the nurses $(2.77 \pm 0.86)$. However, epidemiology obtained the lowest score $(2.47 \pm 0.82)$. In this domain, general issues related to mass casualty management in large-scale disasters (ethical, cultural, legal and safety 
issues) and ability to identify the underlying disease resulting from exposure to chemical, biological and radiological agents obtained $2.52 \pm 1.13$ and $2.39 \pm 1.05$, respectively ${ }^{(25)}$.

Probably, the educational background and the clinical experience of the physicians in the present study could provide them with the opportunity to be familiar with the knowledge and competence in these areas more than nurses. On the other hand, nurses' workload, unclear assignment, and lack of coordination between healthcare team all could be contributing factors that lead them to disregard some aspects of emergency care in these situations. These speculations are consistent with what Gibbie and Qureshi (2006) claimed that responding to emergencies is far more than knowing how to identify the signs and symptoms of traumatic injury or exposure to hazardous chemicals. Effective response requires a disciplined team in which each participating individual follows clear lines of communication and performs according to clearly assigned role directions. Nurses have always been key players during epidemic situations by performing contact tracing and conducting case investigations, engaging in surveillance and reporting, collecting specimens, administering immunizations, and educating the community. Since most health professionals do not respond to emergencies every day, it was necessary for nursing to identify the core abilities needed to become a part of an emergency response team and perform well ${ }^{(29)}$. To that effect, the International Nursing Coalition for Mass Casualty Education (INCMCE) (Vanderbilt University, 2003) was established to take on the task of clarifying exactly what should be included in the undergraduate nursing curriculum to assure communities that their professional nurses were competent to respond when needed ${ }^{(30)}$.

Unlike the findings of the present study, the results of Ibrahim (2014) showed that nurses scored better in decontamination $(75.8 \%)$, preparedness terms and activities $(75.7 \%)$, ethical issues in triage $(57.7 \%)$, incident command system and role within it $(75.5 \%)$ and communication/connectivity $(70.3 \%)^{(31)}$. Slepski (2007) found that basic clinical care $(39 \%)$ and triage $(26 \%)$ as the most frequent response skills reported by the registered nurses and physicians; the areas wherein respondents felt least prepared were disaster-specific response skills $(22 \%)$ and systems issues (34\%). Only $22 \%$ of respondents reported that they did not know a specific skill such as Advanced Cardiac Life Support or triage ${ }^{(17)}$.

Furthermore, the findings of present study showed that, accessing to critical resources was the least rated domain by the participants, which was significantly unfamiliar to physicians than nurses. Wisniewski et al. (2004), Ibrahim (2014), Garbutt et al. (2008) reported similar findings to the current authors' study. It seems that lack of network that linked all healthcare organizations in Egypt as well as absence of data base to help healthcare providers to have access to all the needed resources and information could be the reason for such defect ${ }^{(18,31,32)}$.

\section{Conclusion}

The results showed that both nurses and physicians had significant gaps in their familiarity with the emergency preparedness in disaster management and raised concerns about lack of training, unavailability of strategic and operational plans, and unfamiliarity with roles, procedures and assignment in disaster situations. Furthermore, all the demographic and professional characteristics of the participants had no significant associations with the overall familiarity with readiness in managing disasters.

\section{Recommendations}

The followings are the main recommendations yielded by this study:

- Knowledge and competencies are required particularly on how to access to critical resources. In addition, the 
other domains of EPIQ should be included in the academic healthcare curricula and the training programs of the future healthcare providers.

- Demonstrating familiarity with readiness in managing the emergency area should be addressed as prerequisite for the employment in that specialty.

- National health standards and protocols, and strategic and operational plans for practicing with adequate number of qualified workforce in disaster and emergency preparedness as well as coordination between healthcare organizations regarding disaster and emergency preparedness are needed.

- There is a need to develop future research including different groups of participants and using objective and subjective measures to improve the understanding of the results of the present study. 
Table (1): Nurses' and physicians' familiarity with readiness in managing disaster and emergency situations

\begin{tabular}{|c|c|c|c|c|c|c|c|}
\hline \multirow{3}{*}{ Items } & \multicolumn{4}{|c|}{ Group } & \multirow{2}{*}{\multicolumn{2}{|c|}{ Total }} & \multirow{3}{*}{$\mathbf{t}(\mathbf{P})$} \\
\hline & \multicolumn{2}{|c|}{ Nurses (216) } & \multicolumn{2}{|c|}{ Physicians (84) } & & & \\
\hline & Mean & SD & Mean & SD & Mean & SD & \\
\hline $\begin{array}{l}\text { Emergency preparedness } \\
\text { terms and activities }\end{array}$ & 2.75 & 0.91 & 3.15 & 0.60 & 2.86 & 0.85 & $\begin{array}{c}2.9 \\
(0.003)^{*}\end{array}$ \\
\hline Incident command system & 2.76 & 0.92 & 2.66 & 0.81 & 2.73 & 0.87 & $\begin{array}{c}1.1 \\
(0.529)\end{array}$ \\
\hline Ethical issues in triage & 2.76 & 0.84 & 3.58 & 0.77 & 2.99 & 0.90 & $\begin{array}{c}4.2 \\
(<0.001)^{*} \\
\end{array}$ \\
\hline $\begin{array}{l}\text { Epidemiology and } \\
\text { surveillance }\end{array}$ & 2.76 & 0.94 & 3.55 & 0.66 & 2.98 & 0.95 & $\begin{array}{c}4.2 \\
(<0.001)^{*}\end{array}$ \\
\hline Isolation/quarantine & 2.66 & 1.04 & 2.50 & 0.96 & 2.61 & 1.02 & $\begin{array}{c}1.2 \\
(0.413)\end{array}$ \\
\hline Decontamination & 2.69 & 0.96 & 2.59 & 0.88 & 2.66 & 0.94 & $\begin{array}{c}1.0 \\
(0.566)\end{array}$ \\
\hline $\begin{array}{l}\text { Communicational } \\
\text { connectivity }\end{array}$ & 2.60 & 0.89 & 2.55 & 0.78 & 2.58 & 0.86 & $\begin{array}{c}0.98 \\
(0.760) \\
\end{array}$ \\
\hline Psychological issues & 2.75 & 0.92 & 2.77 & 0.88 & 2.76 & 0.91 & $\begin{array}{c}0.21 \\
(0.904)\end{array}$ \\
\hline Special populations & 2.68 & 0.94 & 2.75 & 0.87 & 2.70 & 0.92 & $\begin{array}{c}0.89 \\
(0.679)\end{array}$ \\
\hline $\begin{array}{l}\text { Accessing to critical } \\
\text { resources }\end{array}$ & 2.59 & 1.04 & 2.10 & 0.74 & 2.44 & 0.99 & $\begin{array}{c}3.1 \\
(0.001)^{*}\end{array}$ \\
\hline Overall familiarity & 2.60 & 1.10 & 2.48 & 0.87 & 2.56 & 1.04 & $\begin{array}{c}1.2 \\
(0.540)\end{array}$ \\
\hline $\begin{array}{l}\text { Overall self-perceived } \\
\text { knowledge }\end{array}$ & 2.69 & 0.80 & 2.78 & 0.56 & 2.72 & 0.74 & $\begin{array}{c}1.3 \\
(0.483)\end{array}$ \\
\hline
\end{tabular}

$\mathrm{t}$ : independent samples t-test

$* \mathrm{P}<0.05$ (significant) 
Table (2): Nurses' and physicians' responses of barriers and recommendations for improving of readiness in managing disaster and emergency situations

\begin{tabular}{|c|c|c|c|c|c|}
\hline \multirow[t]{2}{*}{ Items } & \multicolumn{2}{|c|}{$\begin{array}{c}\text { Nurses } \\
(\mathbf{1 0 8})\end{array}$} & \multicolumn{2}{|c|}{$\begin{array}{l}\text { Physicians } \\
\text { (42) }\end{array}$} & \multirow[t]{2}{*}{$X^{2}(\mathbf{P})$} \\
\hline & No. & $\%$ & No & $\%$ & \\
\hline \multicolumn{6}{|l|}{ Barriers } \\
\hline $\begin{array}{l}\text { Unavailability of national health standards, protocols, } \\
\text { strategic or operational plans related to disaster management. }\end{array}$ & 94 & 87.0 & 36 & 85.7 & $\begin{array}{c}0.87 \\
(0.847) \\
\end{array}$ \\
\hline $\begin{array}{l}\text { Insufficient resources (space, equipment and new } \\
\text { technology). }\end{array}$ & 37 & 34.3 & 22 & 52.4 & $\begin{array}{c}3.1 \\
(0.165) \\
(16)\end{array}$ \\
\hline $\begin{array}{l}\text { Never take part of with regard to setting up and running of } \\
\text { disaster \&emergency preparedness (training, drills, etc.). }\end{array}$ & 73 & 67.6 & 32 & 76.2 & $\begin{array}{c}2.4 \\
(0.399) \\
\end{array}$ \\
\hline $\begin{array}{l}\text { Difficulty in communication and coordination among } \\
\text { healthcare providers. }\end{array}$ & 30 & 27.8 & 13 & 31.0 & $\begin{array}{c}1.87 \\
(0.517)\end{array}$ \\
\hline $\begin{array}{l}\text { Unfamiliarity with the emergency roles, procedures, and } \\
\text { assignments. }\end{array}$ & 98 & 90.7 & 39 & 92.8 & $\begin{array}{c}0.11 \\
(0.927)\end{array}$ \\
\hline \multicolumn{6}{|l|}{ Recommendations for improvement } \\
\hline $\begin{array}{l}\text { Following national standards, strategic and operational work } \\
\text { plans, policies and guidelines. }\end{array}$ & 93 & 86.1 & 37 & 88.1 & $\begin{array}{c}1.5 \\
(0.869)\end{array}$ \\
\hline Better coordination among healthcare organizations. & 63 & 58.3 & 24 & 73.8 & $\begin{array}{c}0.87 \\
(0.983) \\
\end{array}$ \\
\hline Better work organization in disaster and emergency events. & 88 & 81.5 & 31 & 73.8 & $\begin{array}{c}2.1 \\
(0.437) \\
\end{array}$ \\
\hline $\begin{array}{l}\text { Planned trainings for healthcare providers (e.g., first aid, } \\
\text { triage, CPR, etc.). }\end{array}$ & 100 & 92.6 & 35 & 83.3 & $\begin{array}{c}5.9 \\
(0.502) \\
(0.502 \\
\end{array}$ \\
\hline Need for adequate number of qualified healthcare providers. & 84 & 77.8 & 37 & 88.1 & $\begin{array}{c}2.0 \\
(0.448)\end{array}$ \\
\hline $\begin{array}{l}\text { Designed content related to disaster and emergency } \\
\text { preparedness in the undergraduate healthcare curricula. }\end{array}$ & 79 & 73.1 & 33 & 78.6 & $\begin{array}{c}1.8 \\
(0.792) \\
\end{array}$ \\
\hline
\end{tabular}

P: Pearson's $X^{2}$ test $\quad \mathrm{P}$ value based on Fisher exact probability * significant $\mathrm{P}$ 
Emergency Preparedness and Perceived Competence in Disaster

Table (3): Mixed linear regression models of demographic and professional characteristics and overall of nurses' and physicians' familiarity with emergency and disaster preparedness

\begin{tabular}{|c|c|c|c|c|c|c|c|c|}
\hline \multirow{2}{*}{ Group } & \multirow{2}{*}{ Items } & \multicolumn{2}{|c|}{ Unstandardized Coefficients } & \multirow{2}{*}{$\begin{array}{c}\begin{array}{c}\text { Standardized } \\
\text { Coefficients }\end{array} \\
\text { Beta }(\beta) \\
\end{array}$} & \multirow{2}{*}{$\mathrm{t}$} & \multirow{2}{*}{ Sig. } & \multicolumn{2}{|c|}{ Collinearity Statistics } \\
\hline & & B & Std. Error & & & & Tolerance & VIF \\
\hline \multirow[t]{8}{*}{ Nurses } & Constant/predictor (a) & 109.502 & 60.052 & & 1.823 & .071 & & \\
\hline & Age & -0.165 & 1.022 & -0.037 & -0.161 & .872 & 0.173 & 5.797 \\
\hline & Sex (Female) & 32.362 & 12.577 & 0.261 & 2.565 & .012 & 0.859 & 1.165 \\
\hline & \begin{tabular}{|l|} 
Educational level \\
\end{tabular} & -5.346 & 3.580 & -0.143 & -1.493 & .139 & 0.971 & 1.030 \\
\hline & Unit experience & -0.560 & 1.133 & -0.111 & -0.494 & .622 & .175 & 5.723 \\
\hline & Training & -11.123 & 23.958 & -0.044 & -0.464 & .643 & 0.994 & 1.006 \\
\hline & ANOVA(c) (Familiarity) & R Square $\left(\mathbf{R}^{2}\right)$ & $\begin{array}{l}\text { Adjusted R } \\
\text { Square }\end{array}$ & $\begin{array}{l}\text { Std. error of the } \\
\text { estimate }\end{array}$ & $\mathrm{F}$ & Sig. & & \\
\hline & & 0.096 & 0.052 & 33.47185 & 2.176 & 0.063 & & \\
\hline \multirow[t]{8}{*}{ Physicians } & Constant/predictor (b) & 34.235 & 69.933 & & 0.490 & 0.643 & & \\
\hline & Age & 3.488 & 2.529 & 0.330 & 1.379 & 0.176 & 0.426 & 2.345 \\
\hline & Sex (Female) & -8.870 & 7.695 & -0.182 & -1.153 & 0.257 & 0.978 & 1.022 \\
\hline & Educational level & 3.935 & 8.185 & 0.098 & 0.481 & 0.634 & 0.591 & 1.693 \\
\hline & Unit experience & -3.650 & 2.707 & -0.313 & -1.348 & 0.186 & 0.454 & 2.202 \\
\hline & Training & 5.476 & 12.072 & 0.073 & 0.454 & 0.653 & 0.945 & 1.058 \\
\hline & ANOVA(c) (Familiarity) & R Square $\left(\mathbf{R}^{2}\right)$ & $\begin{array}{c}\text { Adjusted R } \\
\text { Square }\end{array}$ & $\begin{array}{c}\text { Std. error of the } \\
\text { estimate }\end{array}$ & $\mathrm{F}$ & Sig. & & \\
\hline & & 0.121 & -0.001 & 24.63629 & 0.992 & 0.436 & & \\
\hline \multicolumn{9}{|c|}{ a Predictors: (Constant), Age, Sex, Education, Unit Experience, Training } \\
\hline \multicolumn{9}{|c|}{ b Predictors: (Constant), Age, Sex, Education, Unit Experience, Training } \\
\hline \multicolumn{9}{|c|}{ c Dependent variable: Overall familiarity } \\
\hline
\end{tabular}




\section{References}

1. Guerdan BR. Disaster preparedness and disaster management: The development and piloting of a self-assessment survey to judge the adequacy of community-based physician knowledge. The American Journal of Chinese Medicine 2009; 6: 3240 .

2. Broz D, Levin EC, Mucha AP, Pelzel D, Wong W, Perksy V. Lessons learned from Chicago's emergency response to mass evacuations caused by Hurricane Katrina. American Journal of Public Health 2009; 99:1496-504.

3. Powers R. Evidence-based ED disaster planning. Journal of Emergency Nursing 2009; 35: 218-23.

4. Furin, MA, Brenner, BE. Disaster planning. Medscape: News \& Perspective. Available on:

http://emedicine.medscape.com/article/765 495-overview. Retrieved on: May, 20, 2016.

5. Schwartz MD. The impact of correctional institutions on public health during a pandemic or emerging infection disaster. American Journal of Disaster Medicine 2008; 3: 165-70.

6. Slepski LA. Emergency preparedness: Concept development for nursing practice. Nursing Clinicians of North American 2005; 40: 419-30.

7. Bernstein D. Rethinking the physician's duty in disaster care. Virtual Mentor 2010; 12: 460-65.

8. Lavin RP. HIPPA and disaster research: Preparing to conduct research. Disaster Management \& Response 2006; 4: 32-6.

9. Gebbie KM, Qureshi K. Emergency and disaster preparedness: Core competencies for nurses. What every nurse should know but may not know. The American journal of Nursing 2002; 102: 46-51.

10. Baack ST. Analysis of Texas nurses' preparedness and perceived competence in managing disasters. Published Doctoral Dissertation. The University of Texas at Tyler, College of Nursing and Health Sciences, 2011; 6-98.

11. American Medical Association. Opinion 9.067 Physician Obligation in Disaster Preparedness and Response. Code of Medical Ethics. Chicago, IL: American Medical Association; 2008-2009. Available on: $\quad$ http://www.amaassn.org/ama/pub/physicianresources/medical-ethics/codemedicalethics/. Retrieved Dec. 20, 2015.

12. Wynd CA. A proposed model for military disaster nursing. Online Journal of Issues in Nursing 2006; 11. Available at: www.nursingworld.org/ojin/topic31_4.htm. Retrieved on: Jan. 24, 2016.

13. Daily E, Padjen P, Birnbaum M. A review of competencies developed for disaster healthcare providers: Limitations of current processes and applicability. Prehospital and Disaster Medicine 2010; 25: 387-95.

14. Columbia University School of Nursing Center for Health Policy. Bioterrorism and emergency preparedness: Competencies for all public health workers. New York: Center for Health Policy, 2002.

15. Bahrami M, Aliakbari F, Aein F. Investigation of competencies of nurses in disaster response by utilizing objective structured clinical examination. Iranian Journal of Nursing and Midwifery Research 2014; 19: S1-6. PMCID: PMC4402988.

16. Markenson D, DiMaggio C, Redlener I. Preparing health professions students for terrorism, disaster, and public health emergencies: Core competencies. Academic Medicine 2005; 80: 517-26.

17. Slepski LA. Emergency preparedness and professional competency among health care providers during hurricanes Katrina and Rita: pilot study results. Disaster Management \& Response 2007; 5: 99-110. 
1. Wisniewski R, Dennik-Champion G., Peltier J. Emergency preparedness competencies assessing nurses' educational needs. Journal of Nursing Administration 2004a; 34: 475-80.

2. Sauer LM, McCarthy ML, Knebel A, Brewster P. Major influences on hospital emergency management and disaster preparedness. Disaster Medicine and Public Health Preparedness 2009; 3: S68.

3. Barbera JA, Yeatts DJ, Macintyre AG. Challenge of hospital emergency preparedness: Analysis and recommendations. Disaster Medicine and Public Health Preparedness 2009; 3: S74.

4. Razzak JA, Kellermann AL. Emergency medical care in developing countries: Is it worthwhile? Bulletin of World Health Organization 2002; 80: 900-5.

5. The Egyptian Cabinet - Information and Decision Support Center (IDSC). Egypt's review in depth assessment of progress in disaster risk reduction, 2008, 12. Available at: http://www.preventionweb.net/english/ hyogo/gar/backgroundpapers/document s/Chap5/in-depth-reviews/Egypt.pdf. Retrieved on: Jan. 20, 2016.

6. Abd Elazeem H, Adam S, Mohamed G. Awareness of hospital internal disaster management plan among health team members in a university hospital. Life Science 2011; 8: 42-52.

7. Diab GM, Mabrouk SM. The effect of guidance booklet on knowledge and attitudes of nurses regarding disaster preparedness at hospitals. Journal of Nursing Education and Practice. 2015; 5: 17-31.

8. Seyedin H, Dolatabadi, ZA, Rajabifard F. Emergency nurses' requirements for disaster preparedness. Trauma Monthly 2015; 20(4): e29033. doi: 10.5812/traumamon.29033.
9. Hsia RY, Mbembati NA, Macfarlane S, Kruk ME. Access to emergency and surgical care in sub-Saharan Africa: the infrastructure gap. Health Policy and Planning 2012; 27: 234-44. doi:10.1093/heapol/czr023.

10. Kitt S, Selfridge-Thomas J, Proechl JA, Caiser J. Emergency nursing: A physiologic and clinical perspective. 2nd ed, Philadelphia: W.B. Saunders, 2005 .

11. Baack S, Alfred D. Nurses' preparedness and perceived competence in managing disasters. Journal of Nursing Scholarship 2013, 45: 281-7. doi: 10.1111/jnu.12029.

12. Gebbie KM, Qureshi KA. A historical challenge: Nurses and emergencies. The Online Journal of Issues in Nursing 2006, 11(32). Available on: http://nursingworld.org/MainMenuCate gories/ANAMarketplace/ANAPeriodica 1s/OJIN/TableofContents/Volume11200 6/No3Sept06/NURSESANDEMERGE NCIES.html. Retrieved on: May, 5, 2016.

13. Vanderbilt University School of Nursing. Mass casualty education. International Nursing Coalition for Mass Casualty Education.2003. Available on: www.mc.vanderbilt.edu/nursing/coaliti ons/INCMCE/incmce.html. Retrieved Aug. 4, 2006.

14. Ibrahim FA. Nurses knowledge, attitudes, practices and familiarity regarding disaster and emergency preparedness -Saudi Arabia. Asian Journal of Neurosurgery 2014; 3: 18 25.

15. Garbutt SJ, Peltier JW, Fitzpatrick JJ. Evaluation of an instrument to measure nurses' familiarity with emergency preparedness. Military Medicine 2008; 173: 1073-7. 